\title{
Temperature-Dependent Viscosity and Nanoparticle Effect on Wire Coating Using Third-Grade As a Polymer Liquid With Magnetic Field Flow Within Porous Die
}

\section{Zeeshan Khan ( $\sim$ zeeshan@bkuc.edu.pk)}

Department of Mathematics and Statistics Bacha Khan University Charsadda, KP, Pakistan

Prof. Dr. llyas Khan

Department of Mathematics, College of Science, Al-Zulfi, Majmaah University, Majmaah, 11952, Saudi Arabia

\section{Research Article}

Keywords: RK4 and HAM solutions, Nanofluid, Surface coating, Heat Generation/Observation, Permeability coverig die,Time-dependent Viscosity, Third grade fluid

Posted Date: October 14th, 2021

DOl: https://doi.org/10.21203/rs.3.rs-936673/v1

License: (c) (1) This work is licensed under a Creative Commons Attribution 4.0 International License.

Read Full License 


\title{
Temperature-dependent Viscosity and Nanoparticle Effect on Wire Coating using Third-Grade as a Polymer Liquid with Magnetic Field Flow within Porous Die
}

\author{
Zeeshan Khan*1, Ilyas Khan ${ }^{2}$ \\ 1. Department of Mathematics and Statistics, Bacha Khan University Charsadda, KP, Pakistan \\ 2. Department of Mathematics, College of Science Al-Zulfi, Majmaah University, Al-Majmaah \\ 11952, Saudi Arabia
}

\begin{abstract}
The convective heat and mass propagation inside dies are used to determine the characteristics of coated wire products. As a result, comprehending the properties of polymerization mobility, heat mass transport, and wall stress concentration is crucial. The wire coating procedure necessitates an increase in thermal performance. As a result, this research aims to determine how floating nanoparticles affect the mass and heat transport mechanisms of third-grade fluid in the posttreatment for cable coating processes. For nanofluids, the Buongiorno model is used, including variable viscosity.

The model equations are developed using continuity, momentum, energy, and nanoparticle volume fraction concentration. We propose a few nondimensional transformations that are relevant. The numerical technique Runge-Kutta fourth method is used to generate numerical solutions for nonlinear systems. Pictorial depictions are used to observe the influence of various factors in the nondimensional flow, radiative, and nanoparticle concentration fields. Furthermore, the numerical results are also verified analytically using Homotopy Analysis Method (HAM). The analytical findings of this investigation revealed that within the Reynolds modeling, the stress on the whole wire surface combined with shear forces at the surface predominates Vogel's model. The contribution of nanomaterials upon force on the entire surface of wire and shear forces at the surface appears positive. A non-Newtonian feature can increase the capping substance's velocity. This research could aid in the advancement of wire coating technologies.
\end{abstract}

For the first instance, the significance of nanotechnology during wire coating evaluation is explored utilizing Brownian motion with generation/absorption slip processes. For time-dependent viscosity, two alternative models are useful.

Keywords: RK4 and HAM solutions, Nanofluid, Surface coating, Heat Generation/Observation, Permeability coverig die,Time-dependent Viscosity, Third grade fluid. 


\section{Introduction}

The polyethene coating is frequently functionalized to cables or pipes for corrosion prevention, voltage differential, mechanical characteristics, and environmental legislation. The metal coating technique, in particular, is important in a variety of commercial applications. Coaxial extrusion, immersion, and electromagnetic application are examples of wire surface treatments. During the first two ways, the connection between the spectrum and polymerization is not as strong. As a result, although the electromagnetic deposition technique is quite sluggish, many researchers prefer and recommend it. Figure 1 shows an example of a wire coated unit. The heat and mass transportation in the interior of molds determine the quality of wire products. Missoula is particularly interested in polymerization's momentum features, thermal mass transport, and wall shear forces. Middleman [1], Denn [2], and others have published important mathematical studies on wire-coated assessments in viscous liquids. Akter and Hashmi [3] employed a cylindrical component in the procedure of wire sealant by polymeric flow, which is impacted by numerous factors, including viscosity and unit form. The analytical results for wire sealant extrusion using compression form die in the circulation for third-grade fluid were disclosed by Siddiqui et al. [4] . The appropriate solution for wire covering by extraction from an Oldroyd 8constant tubular reactor was presented by Sajid et al. [5]. They hypothesized that the liquid was subjected to magnetic interaction. The Ellis solvent was used by Ayaz et al. [6] to analyze wire treatment. Using the binomial series method, researchers were able to achieve closed-form results. They also calculated the coating wire thicknesses. Sajid and Hayat [7] described the wire coating evaluation using a Sisko fluid and documented the effect of factors on the velocity and the energy required to draw the cable. By using an Oldroyd 8-constant fluid, Shah et al. [8] investigated the source of differential pressure affecting wire coating. Shah et al. [9] studied the influence of heat transmission on the viscoelastic fluid transformation into wire coatings postintervention. They also took into account a linear variation of heat on the coating ring's surface. Eventually, Shafieenejad et al. [10] expanded on analysis with including $3^{\text {rd }}$-grade liquid reported by Ayaz et al. Wire coating complications with non-

Newtonian fluid has been investigated by Shah et al. [11] and Nayak et al. [12]. Impact of changing viscosity on wire was recently examined by Nayak [13]. They presented viscous fluid and variable thermal conductivity scenarios using Reynolds and Vogel's framework. Surprisingly, very few wire 
wrapping studies have considered sensible solutions of well-dispersed nanofluids. As a consequence, we concentrated our efforts in the present study to close this gap.

Precincts are common in conventional heat transmission materials. Thermal efficiency is crucial in those areas. Choi [14] developed a new era the heat transfer fluids called nanofluids to address this problem. However, he stated that with a small volume proportion of nanomaterials (5\%), the thermal efficiency of the base fluid could be increased by 10 to $50 \%$. Buongiorno [15] investigated convective movement in nano liquid to determine the cause of an upsurge in heat capacity. He emphasized the significance of mechanisms including Brownian movement and thermal radiation. Numerous researchers have since used this framework exhaustively, such as (Kuznetsov.and Nield [16], Sheikholeslami.and Ganji [17], Ellahi et al. [18], Shehzad et al. [19], Zeeshan et al. [20], Zeeshan et al. [21], Zeeshan et al. [22], Sheikholeslami.and Ellahi [23], Hussain et al. [24], Gireesha et al. [25], Ellahi et al. [26], Hayat.et al. [27], Ellahi et al. [28], Zeeshan et al. [29], Zeeshan et al. [30], Mahanthesh et al. [31], Turkyilmazoglu.[32], Mahanthesh.et al. [33],.Shirvan et al..[34], Muhammad et al. [35], Shirvan et al. [36], Turkyilmazoglu.[37],. Mitsoulis [38],.Shirvan.et al..[39, 40], Mahanthesh.et al..[41], Khan.et al..[42], Hayat et al. [43] and Muhammad et al. [44] to examine various aspect of nanofluids flow.

This investigation aims to examine the influence of nanomaterials on magnetohydrodynamic ThirdGrade fluid in a pressurized die during wire surface covering using Brownian motion and heat conduction. Reynolds, as well as Vogel's models, compensate for variable viscosity as well. Such an endeavour has still not been constructed to contribute. Before being analytically attempted, the relevant resulting equations are made dimensionless by suitable transformation factors. The effect of various parameters accessing the problem is investigated in two situations: (1) the Reynolds model and (2) Vogel's model.

\section{Modeling ofthe Problem}

It is postulated that a third-grade fluid-filled with nanoscale material flows within a fixed compression type die with length L. Due to the obvious, immutable pressure disparity and radially magnetized, nature movement is formed. The cylindrical reference system is used, with longitudinal axis $\mathrm{z}$ aligned with fluid movement and peripheral direction $r$ aligned with it (see Figure 1). The location of the continuum is believed to be concentrically situated. (Rw, $\theta \mathrm{w}, \phi \mathrm{w})$ and $(\mathrm{Rd}, \theta \mathrm{d}, \phi \mathrm{d})$ are the radius, 
temperature, and volume fraction of the rope and dying, respectivly.

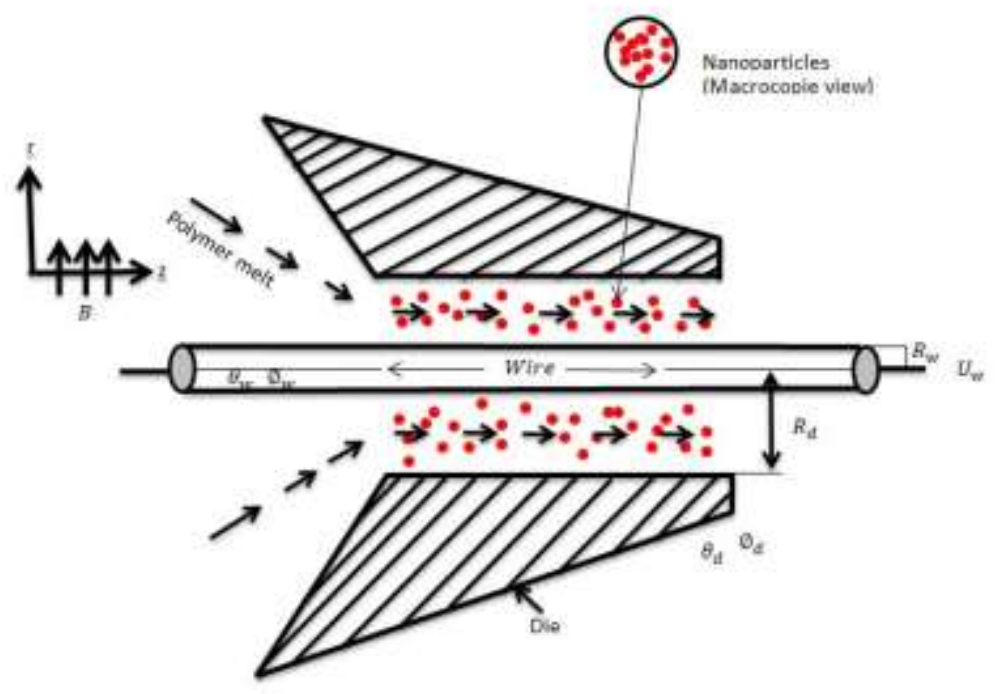

Figure 1. Two-phase coating geometry.

Uw is also the speed of this wire as it is inserted along the central path of the machine. The emulsion polymerization flow should be axisymmetric, continuous, and homogeneous. Nayak et al.and Nayak $[13,12]$ evaluated the velocity, additional stress tensor, heating rate, and volume fraction of nanomaterials :

$$
\stackrel{\mathbf{u}}{w}=[0,0, \mathrm{w}(r)], S=S(r), T=T(r) .
$$

Subject to constraints

$$
\begin{aligned}
& w=U w, \theta=\theta w, \phi=\phi w \text { at } r=R w \\
& w=0, \theta=\theta d, \phi=\phi d \text { at } r=R d
\end{aligned}
$$

Regarding Third-grade liquid, the stress tensor $\mathrm{S}$ is described as

$$
S=\eta A_{1}+\alpha_{1} A_{2}+\alpha_{2} A_{1}+\tau_{1} A_{2}+\tau_{2}\left(A_{1} A_{2}+A_{2} A_{1}\right)+\tau_{3}\left(\operatorname{tr} A_{2}\right) A_{1},
$$

The governing parameters that apply are as follows [5-12]:

$$
\nabla \cdot w=0
$$




$$
\begin{aligned}
& \rho_{f} \frac{\stackrel{\mathbf{l}}{D q}}{D t}=\stackrel{\stackrel{\mathbf{r}}{\nabla}}{D t}+\stackrel{\mathbf{u}}{F}+\stackrel{\mathbf{u}}{J} \times \stackrel{\mathbf{u r}}{B} \\
& \left(\rho c_{p}\right)_{n f} \frac{D \theta}{D t}=k \nabla^{2} \theta+\phi+\left(\rho c_{p}\right)_{n f}\left[D_{B} \nabla \theta \cdot \nabla \phi+\left(\frac{D T}{\theta d}\right) \nabla \theta . \nabla \theta\right], \\
& \frac{D \phi}{D t}=D_{b} \nabla^{2} \phi+\left(\frac{D_{T}}{\theta_{d}}\right) \nabla^{2} \theta .
\end{aligned}
$$

The parameters involved in the above equations are defined in the nomenclature given at the end of the article.

The electrical field is presented in a positive radially normal direction toward the wire, and the resultant magnetic force is believed to be insignificant. As a result, effective body force is determined by:

$$
\stackrel{\mathbf{u}}{J} \times \stackrel{\mathbf{u}}{B}=\left(0,0,-\sigma B_{0}^{2} w\right) .
$$

The dissipation factor with tensor components is as follows:

$$
\begin{aligned}
& S_{r z}=\mu \frac{d w}{d r}+2\left(\beta_{2}+\beta_{3}\right)\left(\frac{d w}{d r}\right)^{3}, \\
& S_{r r}=\left(\alpha_{2}+2 \alpha_{1}\right)\left(\frac{d w}{d r}\right)^{2}, \\
& S_{z z}=\alpha_{2}\left(\frac{d w}{d r}\right)^{2} \\
& \phi=\mu\left(\frac{d w}{d r}\right)^{2}+2\left(\beta_{2}+\beta_{3}\right)\left(\frac{d w}{d r}\right)^{4},
\end{aligned}
$$

In light of the foregoing relationships, equation of motion (5) yields:

$$
\begin{aligned}
& 2\left(\beta_{2}+\beta_{3}\right) \frac{d}{d r}\left(r\left(\frac{d w}{d r}\right)^{3}\right)+\frac{\eta}{r} \frac{d}{d r}\left(r \frac{d w}{d r}\right)-\sigma B_{0}^{2} u=\frac{d p}{d z} \\
& -2\left(\alpha_{2}+\alpha_{3}\right) \frac{\eta}{r} \frac{d}{d r}\left(r \frac{d w}{d r}\right)=\frac{d p}{d r} .
\end{aligned}
$$

The flow is caused by the pressure difference, as shown by expression (13). Because there is just pull of a wire after it leaves the die, the pressure difference axially is insignificant. As a result, expression (13) 
can be reduced to:

$$
2\left(\beta_{2}+\beta_{3}\right) \frac{d}{d r}\left(r\left(\frac{d w}{d r}\right)^{3}\right)+\frac{\eta}{r} \frac{d}{d r}\left(r \frac{d w}{d r}\right)-\sigma B_{0}^{2} u=0,
$$

In view of Eq. (10), the energy Eq. (7) becomes

$$
\begin{gathered}
k\left(\frac{d^{2} \theta}{d r^{2}}+\frac{1}{r} \frac{d \theta}{d r}\right)+\mu\left(\frac{d w}{d r}\right)^{2}+2\left(\beta_{2}+\beta_{3}\right)\left(\frac{d w}{d r}\right)^{4}+\left(\rho c_{p}\right)_{f}\left(D_{B} \frac{d \theta}{d r} \frac{d \phi}{d r}+\frac{D_{T}}{\theta_{d}}\left(\frac{d \theta}{d r}\right)^{2}\right)=0, \\
D_{B}\left(\frac{d^{2}}{d r^{2}}+\frac{1}{r} \frac{d}{d r}\right) \phi+\frac{D_{T}}{\theta_{d}}\left(\frac{d^{2} \theta}{d r^{2}}+\frac{1}{r} \frac{d \theta}{d r}\right)=0 .
\end{gathered}
$$

The shear force at the wire's surface is calculated as follows:

$$
\left.S_{r z}\right|_{r=R_{w}}=\mu \frac{d w}{d r}+\left.2\left(\beta_{2}+\beta_{3}\right)\left(\frac{d w}{d r}\right)^{3}\right|_{r=R_{w}},
$$

The force acting on the die's total wire exterior is as described in the following:

$$
F_{w}=\left.2 \pi R_{w} L S_{r z}\right|_{r=R_{w}} .
$$

Furthermore, the Nusselt number Nu r has the following definition:

$$
N_{w_{r}}=\frac{r q w}{K\left(\theta_{d}-\theta_{w}\right)}
$$

Where

$q_{d}=-\left.k\left(\frac{d \theta}{d r}\right)\right|_{r=R_{w}}$ is the heat flow at the wire's surface. We propose to explore temperature dependent viscosity in this work, as previously stated. As a result, two additional cases are investigated.

\section{Case 1: Reynolds Model}

Nondimensional viscosity is incorporated in the study as follows Nayak [12]: 


$$
\eta=\exp (-\beta \Omega \theta) \approx 1-\beta \Omega \theta
$$

Where $\Omega$ is renold model parameter.

In light of $(21,22)$, the expressions (15)-(20) should be read as follows (without the asterisks):

$$
\begin{aligned}
& r^{*}=\frac{r}{R_{w}}, w^{*}=\frac{w}{U_{w}}, \beta_{0}=\beta_{2}+\beta_{3}, \frac{R_{d}}{R_{w}}=\delta>1, \beta^{*}=\frac{\beta_{0}^{*}}{\eta\left(\frac{R_{w}^{2} \mu_{0}}{U_{w}^{2}}\right)}, M=\frac{\sigma B_{0}^{2} R_{w}^{2}}{\mu_{0}}, \\
& K=\frac{R_{w}^{2}}{V_{w} K^{*}}, \theta^{*}=\frac{\theta-\theta_{w}}{\theta_{d}-\theta_{w}}, B r=\frac{\mu_{0} U_{w}^{2}}{k\left(\theta_{d}-\theta_{w}\right)}, \mu^{*}=\frac{\mu}{\mu_{0}}, \phi^{*}=\frac{\phi-\phi_{w}}{\phi_{d}-\phi_{w}} \\
& N b=\frac{D_{B}\left(\rho c_{p}\right)\left(\phi_{d}-\phi_{w}\right)}{k}, N t=\frac{D_{T}\left(\rho c_{p}\right)_{f}\left(\theta_{d}-\theta_{w}\right)}{\theta_{d} k}
\end{aligned}
$$

Nondimensional momentum and energy equations with boundary conditions omitting asterisks are

$$
\begin{aligned}
& (1-\beta \Omega \theta)\left(r \frac{d^{2}}{d r^{2}}+\frac{d}{d r}\right) w+2 \beta\left(3 r \frac{d^{2} w}{d r^{2}}\left(\frac{d w}{d r}\right)^{2}+\left(\frac{d w}{d r}\right)^{3}\right)-\beta \Omega r \frac{d \theta}{d r} \frac{d w}{d r}-M w r=0, \\
& \left(\frac{d^{2}}{d r^{2}}+\frac{1}{r} \frac{d}{d r}\right) \theta+(1-\beta \Omega \theta) B r\left(\frac{d w}{d r}\right)^{2}+2 B r \beta\left(\frac{d w}{d r}\right)^{4}+N b \frac{d \theta}{d r} \frac{d \phi}{d r}+N t\left(\frac{d \theta}{d r}\right)^{2}=0, \\
& \frac{d^{2} \phi}{d r^{2}}+\frac{1}{r} \frac{d \phi}{d r}+\frac{N t}{N b}\left(\frac{d^{2}}{d r^{2}}+\frac{1}{r} \frac{d}{d r}\right) \theta=0^{\prime} \\
& w(1)=1, \theta(1)=0, \phi(1)=0, w(\delta)=0, \theta(\delta)=1, \phi(\delta)=1 . \\
& \left.S_{r z}\right|_{r=R_{w}}=\left.\mu \frac{S_{r z} U w}{\mu_{0} R w}\right|_{r=1}=\left.\left[(1-\beta \Omega \theta) \frac{d w}{d r}+2(\beta)\left(\frac{d w}{d r}\right)^{3}\right]\right|_{r=1}, \\
& F_{w}=\left.\frac{F w}{2 \pi R w L}\right|_{r=1}=\left.\left[(1-\beta \Omega \theta) \frac{d w}{d r}+2(\beta)\left(\frac{d w}{d r}\right)^{3}\right]\right|_{r=1},
\end{aligned}
$$

$$
N w_{r}=-\left.\frac{d \theta}{d r}\right|_{r=1}
$$

where $M, B r, \beta, N b$, and $N t$ are the magnetic factor, Brinkman number, non-Newtonian factor, 
Brownian motion factor, and thermophoresis factor, respectively.

\section{Case 2: Vogel's Model}

In this case, the temperature dependent viscosity is taken as

$$
\mu=\mu_{0} \exp \left(\frac{H}{F+\theta}-\theta_{w}\right)
$$

After using the expansion we have

$$
\mu=m\left(1-\frac{H}{F^{2}} \theta\right)
$$

where $m=\mu_{0} \exp \left(\frac{H}{F}-\theta_{w}\right)$ and $\mathrm{H}, F$ are viscosity parameters associated with Vogel's model.

Therefore, the nondimensional momentum and energy equations with boundary conditions omitting, steriks are

$m\left(1-\frac{H}{F^{2}} \theta\right)\left(r \frac{d^{2} w}{d r^{2}}+\frac{d w}{d r}\right)+2 \beta\left(3 r \frac{d^{2} w}{d r^{2}}\left(\frac{d w}{d r}\right)^{2}+\left(\frac{d w}{d r}\right)^{3}\right)-\left(\frac{\mu H}{F^{2}}\right) r \frac{d \theta}{d r} \frac{d w}{d r}-M w r=0$

$\frac{d^{2} \theta}{d r^{2}}+\frac{1}{r} \frac{d \theta}{d r}+m\left(1-\frac{H}{F^{2}} \theta\right) B r\left(\frac{d w}{d r}\right)^{2}+2 B r \beta\left(\frac{d w}{d r}\right)^{4}+N b \frac{d \theta}{d r} \frac{d \phi}{d r}+N t\left(\frac{d \theta}{d r}\right)^{2}=0$

$\frac{d^{2} \phi}{d r^{2}}+\frac{1}{r} \frac{d \phi}{d r}+\frac{N t}{N b}\left(\frac{d^{2}}{d r^{2}}+\frac{1}{r} \frac{d}{d r}\right) \theta=0$,

$w(1)=1, \theta(1)=0, \phi(1)=0, w(\delta)=0, \theta(\delta)=1, \phi(\delta)=1$.

Addionally, equation (26) and (27) become

$$
\left.S_{r z}\right|_{r=R_{w}}=\left.\frac{S_{r z} U w}{\mu_{0} R w}\right|_{r=1}=\left.\left[(1-\beta m \theta) \frac{D}{F^{2}} \theta \frac{d w}{d r}+2 \beta\left(\frac{d w}{d r}\right)^{3}\right]\right|_{r=1}
$$

And 


$$
F_{w}=\left.\frac{F w}{2 \pi R w L}\right|_{r=1}=\left.\left[(1-\beta m \theta) \frac{D}{F^{2}} \theta \frac{d w}{d r}+2(\beta)\left(\frac{d w}{d r}\right)^{3}\right]\right|_{r=1},
$$

\section{Numerical solution}

The Runge-Kutta-Fehlberg strategy is applied to solve the multidegree differential equations system specified in equations (30)-(33). for this purpose following transformations are applied:

$$
\varsigma_{1}=w, \varsigma_{2}=\mathrm{w}^{\prime}, \varsigma_{3}=\theta, \varsigma_{4}=\theta^{\prime}, \varsigma_{5}=\phi \text { and } \varsigma_{6}=\phi^{\prime} \text {. }
$$

As a result, we get the following.

$$
\begin{aligned}
& \zeta_{1}^{\prime}=\varsigma_{2}, \\
& \varsigma_{2}^{\prime}=\frac{\left[M \varsigma_{1} r+\beta \Omega r \varsigma_{2} \varsigma_{4}+\left(\beta \Omega \varsigma_{3}-1\right) \varsigma_{2}-2 \beta \varsigma_{2}{ }^{2}\right]}{r\left[1+M\left(1+6 \beta \varsigma_{2}{ }^{3}-\beta \Omega \varsigma_{3}\right)\right]}, \\
& \varsigma_{3}^{\prime}=\varsigma_{4}, \\
& \varsigma_{4}^{\prime}=-\left(\frac{1}{r} \varsigma_{4}+B r\left(1-\beta \Omega \varsigma_{3}\right) \varsigma_{2}{ }^{2}+2 \beta \Omega B r \varsigma_{2}{ }^{4}+N b \varsigma_{4} \varsigma_{6}+N t \varsigma_{4}{ }^{2}\right), \\
& \varsigma_{5}^{\prime}=\varsigma_{6}, \\
& \varsigma_{6}^{\prime}=-\left(\frac{1}{r} \varsigma_{6}+\frac{N t}{N b}\left(\varsigma_{4}^{\prime}+\frac{1}{r} \varsigma_{4}\right)\right) .
\end{aligned}
$$

Transferred boundary conditions are:

$$
\varsigma_{1}(1)=1, \varsigma_{2}(1)=\alpha_{1}, \varsigma_{3}(1)=0, \varsigma_{4}(1)=\alpha_{2}, \varsigma_{5}(1)=0, \varsigma_{6}(1)=\alpha_{3} .
$$

The best guess estimates for the uncertainties $\alpha_{1}, \alpha_{2}$ and $\alpha_{3}$ are determined, and afterwards, the shooting mechanism is used to determine them. The Runge-Kutta-Fehlberg approach is then used to solve the resulting initial value issue numerically. We used $\Delta \mathrm{r}=0.001$ as that of the scale factor and $10^{-6}$ and $\delta=2$, as the resolution threshold during our computation. 


\section{Validation of the Results}

The technique's consolidation is also required for testing the methodology's trustworthiness. Figures 2a$2 \mathrm{~b}$ depict the convergence of such generated numerical results. The conclusions, as mentioned earlier, are also assessed using an analytical method known as HAM, and the two measurements show a remarkable correlation, as shown in Fig $2 \mathrm{a}$ and $2 \mathrm{~b}$. In addition, Table 1 provides a comparative analysis of numerical and analytic solutions. The current study is compared to previous data [12] for greater precision, and there is a clear consensus, as indicated in Table 1.

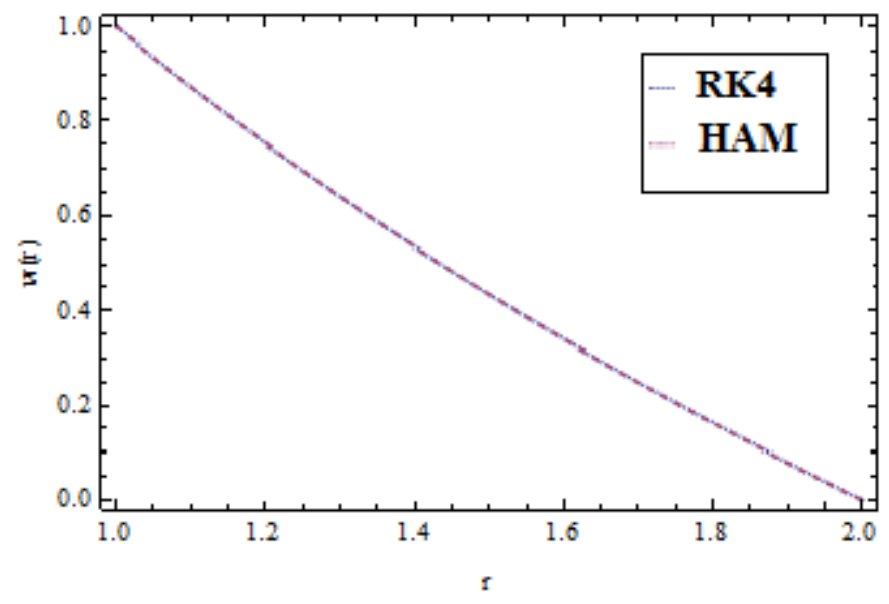

Figure 2a. Comparison of RK4and HAM Methods. 


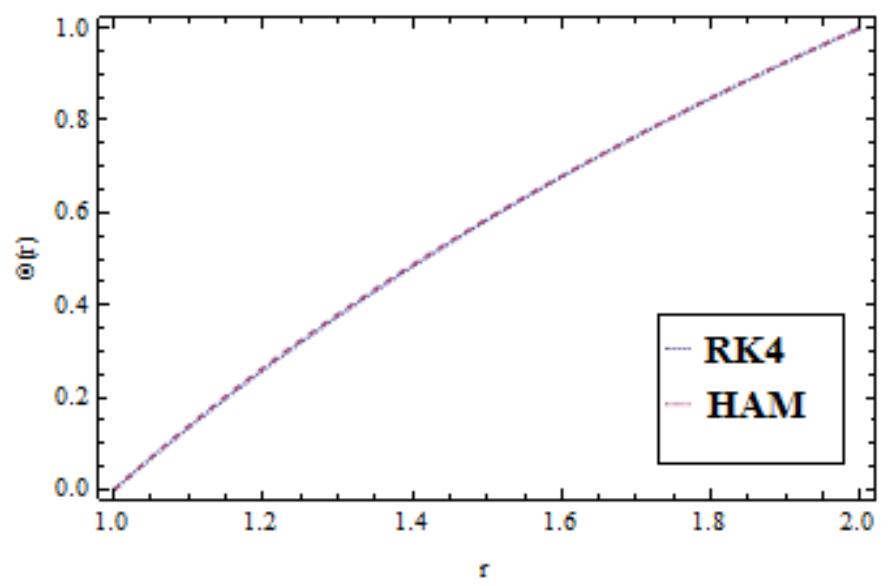

Figure 2b. Comparison of RK4 and HAM Methods.

Table 1. Numerical comparison of HAM, ND-Sole Methods and published work [12].

\begin{tabular}{|l|l|l|l|}
\hline$r$ & RK4 & HAM & $\begin{array}{l}\text { Published } \\
\text { work }\end{array}$ \\
\hline 1.0 & 1 & 1 & 1 \\
\hline 1.2 & 0.57352365 & 0.57352355 & 0.57352355 \\
\hline 1.4 & 0.40325491 & 0.40325480 & 0.40325491 \\
\hline 1.6 & 0.32109323 & 0.32109322 & 0.32109321 \\
\hline 1.8 & 0.21036271 & 0.21036601 & 0.21036270 \\
\hline 2.0 & 0 & $0.0131^{*} 10^{-21}$ & $0.0020^{*-25}$ \\
\hline
\end{tabular}

\section{Results and discussion}

For two scenarios, RM and VM, the effect of essential factors on velocity flow, temperature, and nanoparticle concentration profiles is explored in the presence and absence of magnetic field. The shear stress on the surface of the total wire, and the size of the Nusselt number on the surface, are estimated for both Reynolds and Vogel's model situations. The shear stress on the surface of the total wire is proportional to $w^{\prime}(r)$, as shown by equations (26), (27), (34), and (35). As a result, the shear stress on a total wire surface has the same characteristic as $w^{\prime}(1)$.

Figures 3-5, show the effect of $m$ (viscosity factor of the RM) on the w(r), $\theta(r)$, and $\phi(r)$ distributions, 
respectively. Higher values of $\mathrm{m}$ indicate an increase in $\mathrm{w}(\mathrm{r})$ but a decrease in $\theta(\mathrm{r})$ and $\phi(\mathrm{r})$ profiles. Both the existence and absence of magnetism produce the same descriptive trend. Figure 3 further shows that for a larger $\mathrm{M}$, the $\mathrm{w}(\mathrm{r})$ profile is reduced. The Lorentzian strength (a resistive form of force) increases in magnetic strength increases. As a result of the increased magnetic field, the motion of the polymerization in a die decreases. Furthermore, under the magnetic interaction, $\theta(\mathrm{r})$ and $\phi(\mathrm{r})$ simultaneously demonstrate the dual pattern inside the flow zone. Thus, in the region $1 \leq r<1.4$, both $\theta(r)$ and $\phi(r)$ are stronger, whereas in the region $1.4 \leq r \leq 2$, the tendency is the opposite (see Figures 4 and 5 ). It is worth noting that the results of the current study's flow and thermal measurements match those of Nayak's [12] study on the effect of the friction factor.

Figures 6-8 show a graphical representation of the variances in the w(r), $\theta(\mathrm{r})$, and $\phi(r)$ profiles form. Figure 6 shows that the fluid velocity grows in the region $1 \leq \mathrm{r}<1.5$, but this behavior is reversed in the remainder of the continent for greater values of. Figures 7 and 8 show that increasing $m$ causes the polymer's fields $\theta(\mathrm{r})$ to be enhanced while decreasing the $\phi(\mathrm{r})$ fields. Furthermore, the effect of magnetism is consistent with our prior findings (see Figures 3-5). Furthermore, while comparing the influence of the Reynolds model case and Vogel's model case on the velocity field, we discovered that the velocity profile across the die is enhanced for the Reynolds model, but is constrained somewhat for Vogel's model, especially near the die's boundary.

Figures 9 and 10 show the modification of $\theta(\mathrm{r})$ due to the impact of $\mathrm{Nb}$ inside the Reynolds and Vogel situations, respectively. It is clear that increasing the intensity of $\mathrm{Nb}$ increases the heat transfer in the range $1 \leq \mathrm{r}<1.4$ for Reynolds and Vogel's situations, however, the behavior in the rest of the state is the total opposite. Furthermore, in the RM situation, the temperature field, $\theta(r)$, prevails over Vogel's case. With increasing $\mathrm{Nb}$, the stochastic collision among nanoparticles and liquid molecules increases, causing a flow to become heated and the nanoparticle concentration field to decrease (see Figures 11 and 12 ). Furthermore, the magnetism has no discernible effect on the $\phi(r)$ field at any location on the die.

As shown in Figures 13 and 14, the significance of $\mathrm{Nt}$ on $\theta(\mathrm{r})$ is analogous to that of $\mathrm{Nb}$ on $\theta(\mathrm{r})$. The convective heat transfer force is a force that causes nanomaterials to spread into the surrounding fluid as a conslusion of a temperature difference. The enhancement of thermophoretic force causes nanoparticles to migrate deeper into the polymer. As a result, the temperature field increases in nearly 
half of a domain. Figures 15 and 16 show that with greater values of Nt, $\phi(r)$ decreases. This is the case in both circumstances.

Figures 17 and 18 show the effect of $\beta$ on w(r) for Reynold and Vogel's model situations, respectively. The non-Newtonian parameter denominator contains rheological properties. As a result, the fluidity of the polymers decreases as we increase $\beta$. As a result of increasing the non-Newtonian liquid factor, the melting polymer mobility increases. This pattern is qualitatively comparable in both situations; however, the effect of $\beta$ on $w(r)$ is more noticeable in the Reynolds model than in Vogel's case. The non-Newtonian feature implies that the coating structure's movement can be increased.

The influence of $\mathrm{Br}$ on $\theta(\mathrm{r})$ viscosity is seen in Figures 19 and 20 for the Reynolds and Vogel model models, respectively. A larger amount of $\mathrm{Br}$ enhances the $\theta(\mathrm{r})$ profile. $\mathrm{Br}$ denotes the relative value of viscous heating by conduction of heat. Furthermore, in Vogel's case, the thermal profile varies substantially more for $\mathrm{Br}$ than for the RM case. This is validated with the results of studies published by Nayak [12].

Figures 21-25 show the effect of $\beta, \mathrm{M}, \mathrm{Br}, \mathrm{Nb}$ and $\mathrm{Nt}$ on $\theta^{\prime}(1)$ for both $\mathrm{RM}$ and $\mathrm{VM}$ caese. Figures 21 and 22 show that $\theta^{\prime}(1)$ is larger with greater values of $\beta$ and decreases with increasing $M$ in the VM case. Figures 23-25 indicate the effect of $\mathrm{Br}, \mathrm{Nb}$ and $\mathrm{Nt}$ on $\theta^{\prime}$ (1) for $\mathrm{VM}$ and $\mathrm{RM}$. $\theta^{\prime}(1)$ decreases for $\mathrm{Br}, \mathrm{Nb}$, and $\mathrm{Nt}$. This is true in both RM \& VM scenarios. Additionally, in the RM situation, the force at the surface of the total wire plus shear force at the surface are greater than VM.
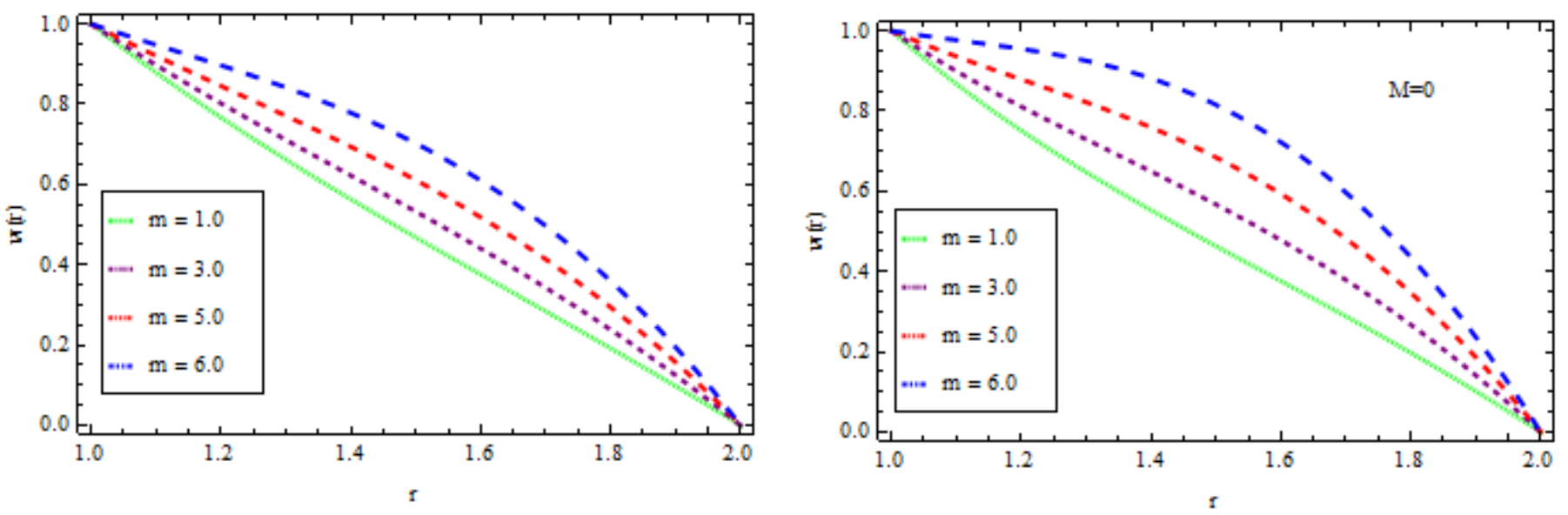

Figure 3. Effect of $\mathrm{m}$ on $\mathrm{w}(\mathrm{r})$ for $\mathrm{RM}$ case. 

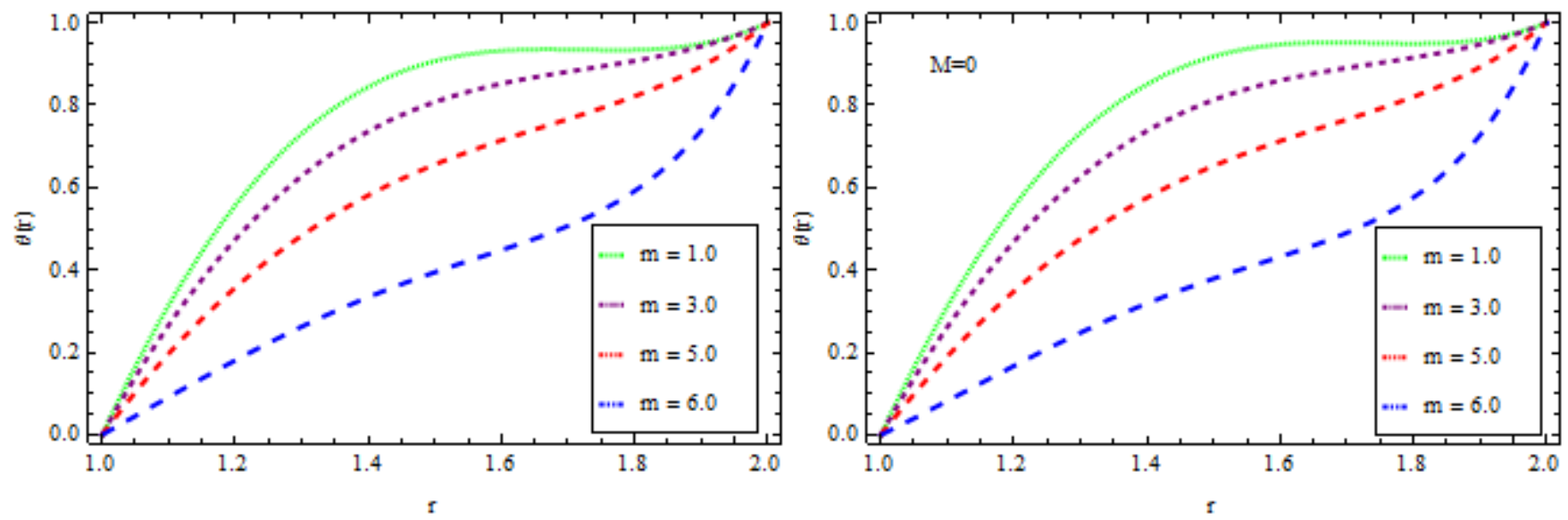

Figure 4. Effect of $m$ on $\theta(r)$ in RM case.
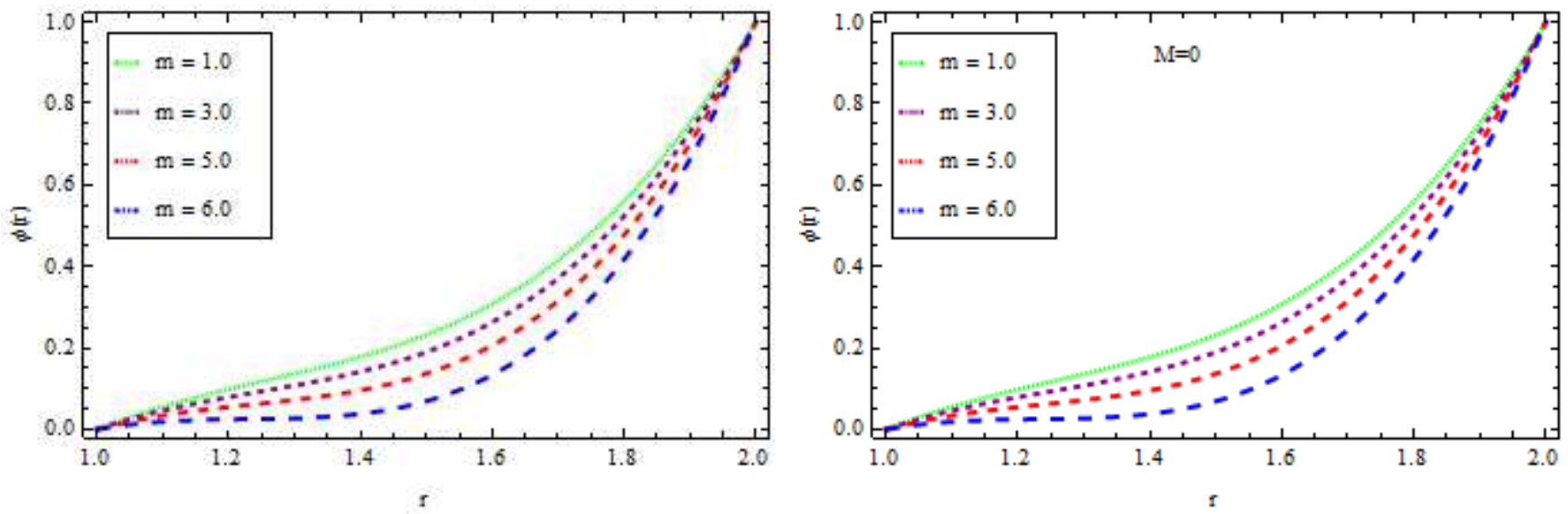

Figure 5. Effect of $m$ on $\phi(r)$ in RM case. 

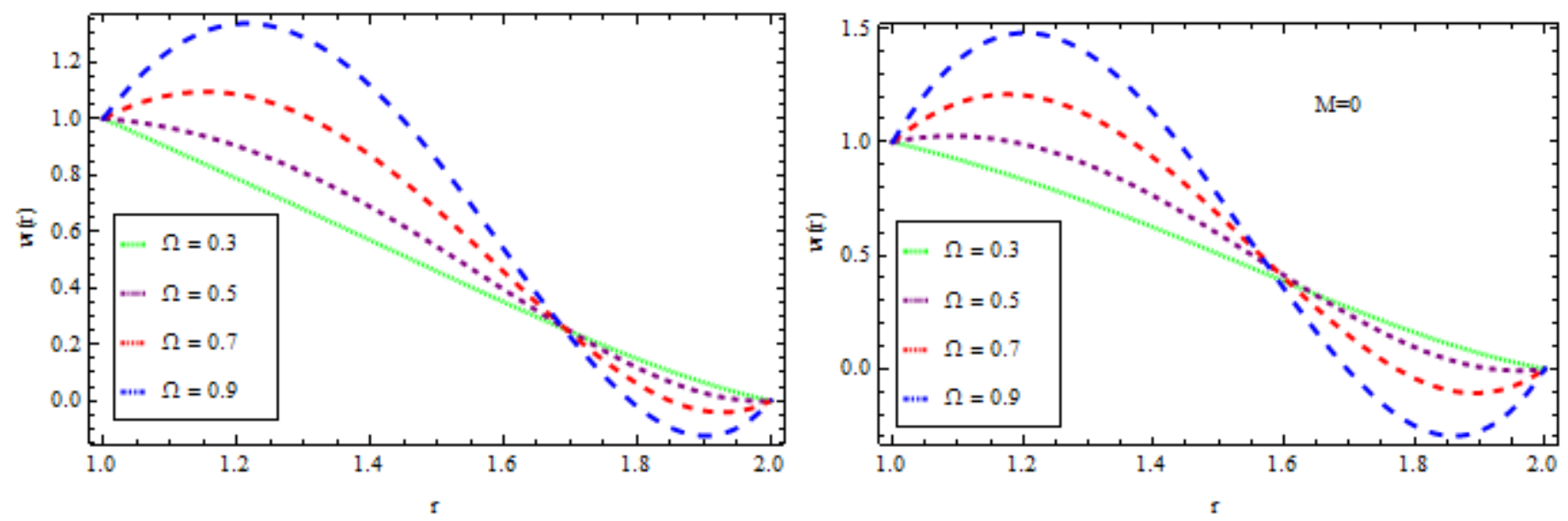

Figure 6. Impcat of $\Omega$ on $\mathrm{w}(\mathrm{r})$ in $\mathrm{VM}$ case.
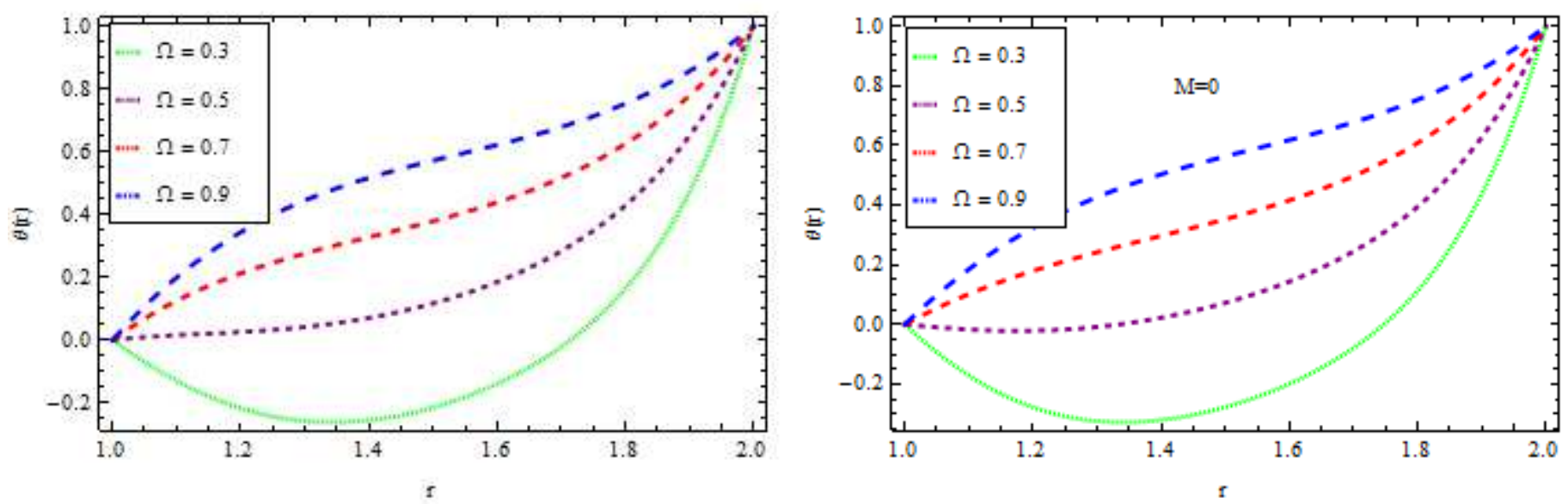

Figure 7. Impcat of $\Omega$ on $\theta(r)$ in VM case. 

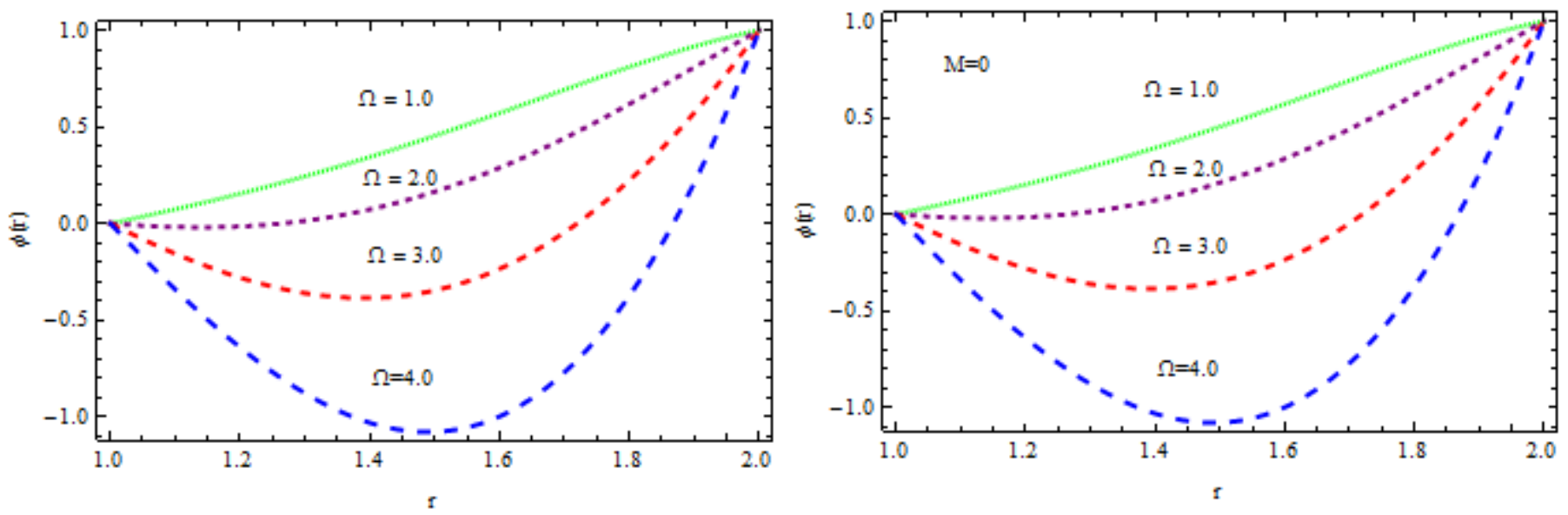

Figure 8. Impcat of $\Omega$ on $\phi(r)$ in $V M$ case.
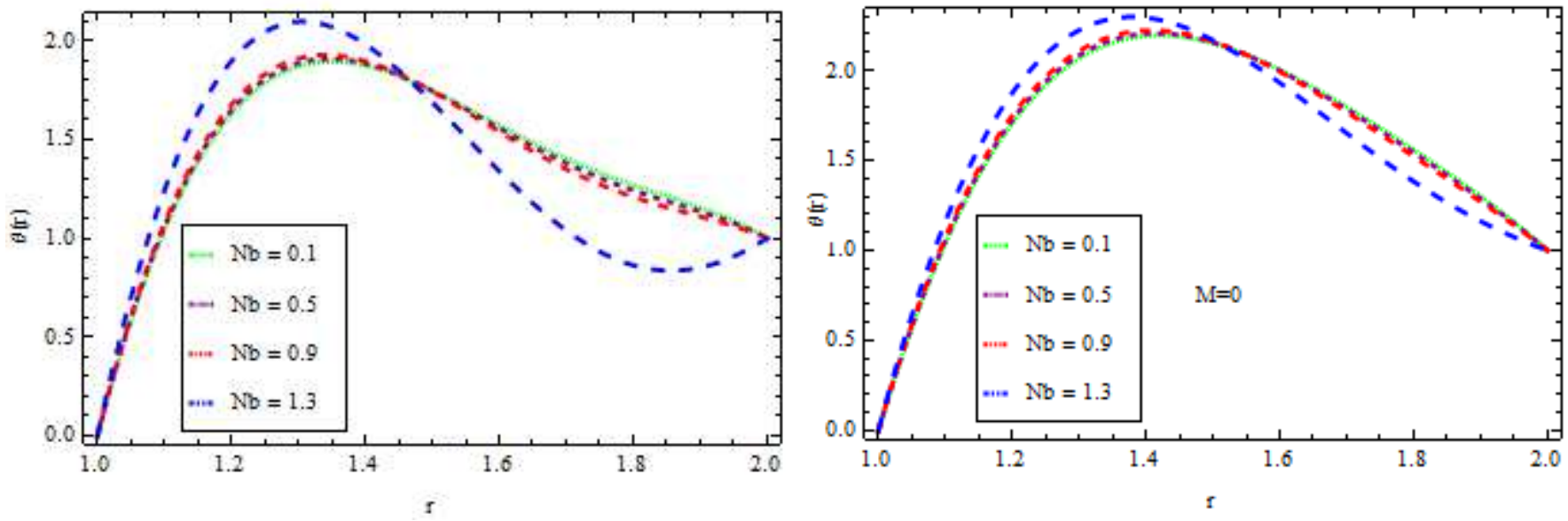

Figure 9. Impcat of $\mathrm{Nb}$ on $\theta(\mathrm{r})$ in $\mathrm{RM}$ case. 

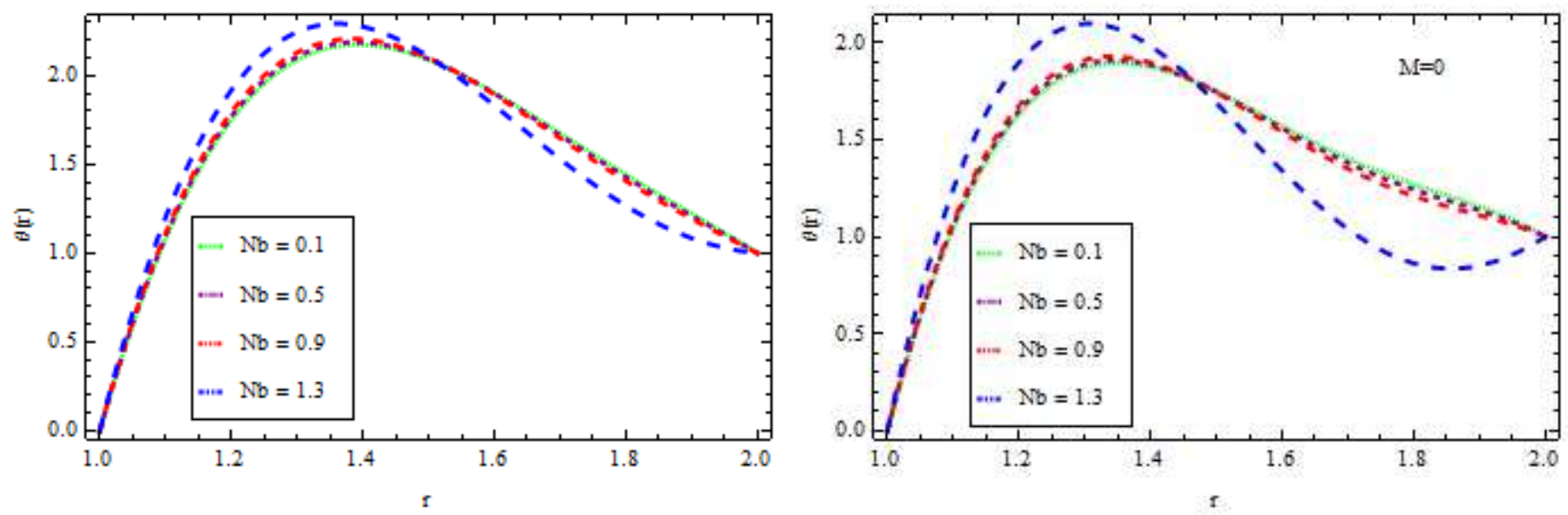

Figure 10. Impcat of $\mathrm{Nb}$ on $\theta(\mathrm{r})$ in $\mathrm{VM}$ case.
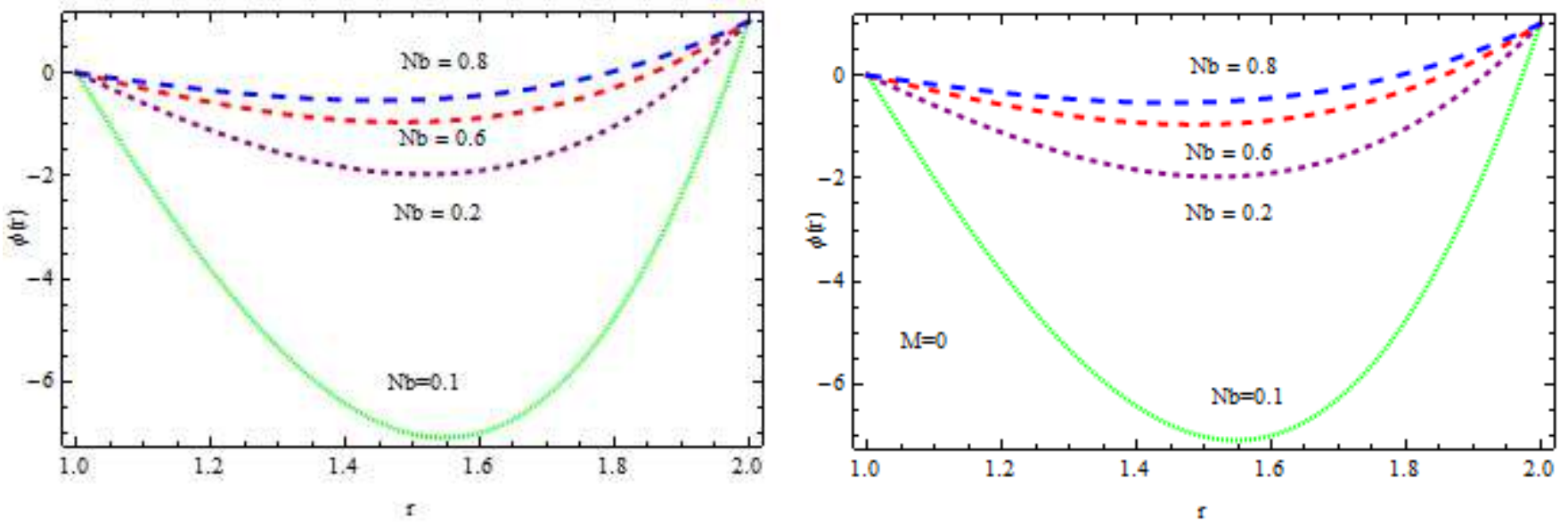

Figure 11. Impcat of $\mathrm{Nb}$ on $\phi(\mathrm{r})$ in $\mathrm{RM}$ case. 

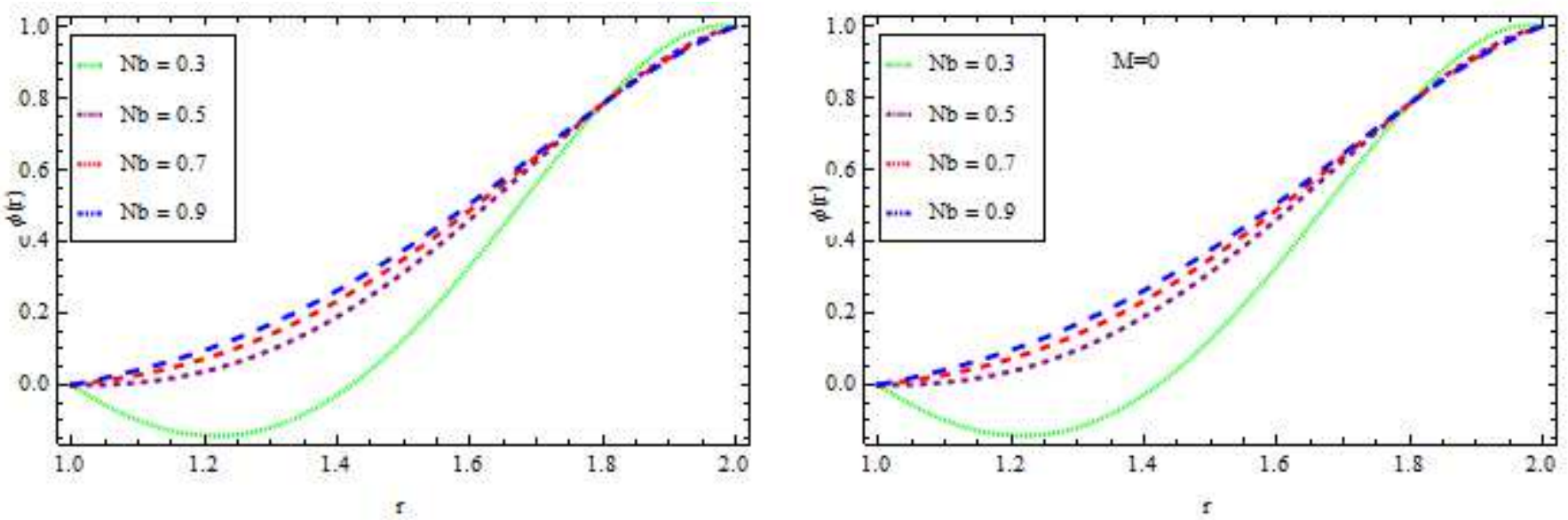

Figure 12. Impcat of $\mathrm{Nb}$ on $\phi(\mathrm{r})$ in $\mathrm{VM}$ case.
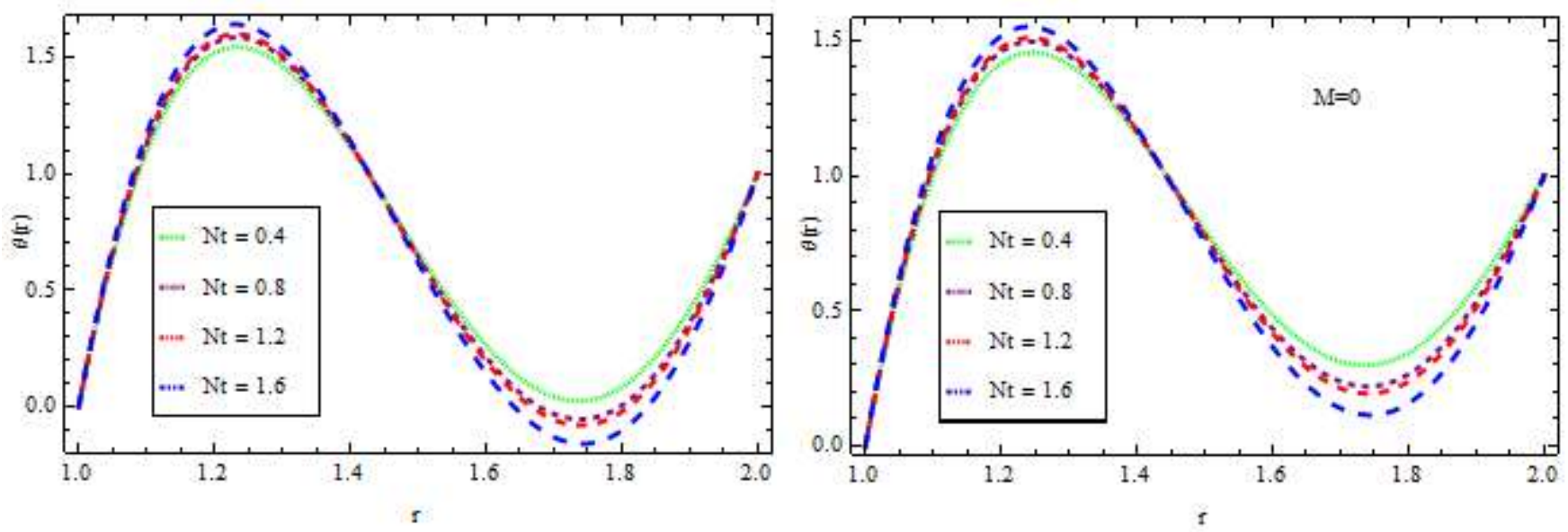

Figure 13. Impcat of Nt on $\theta(r)$ in RM case. 

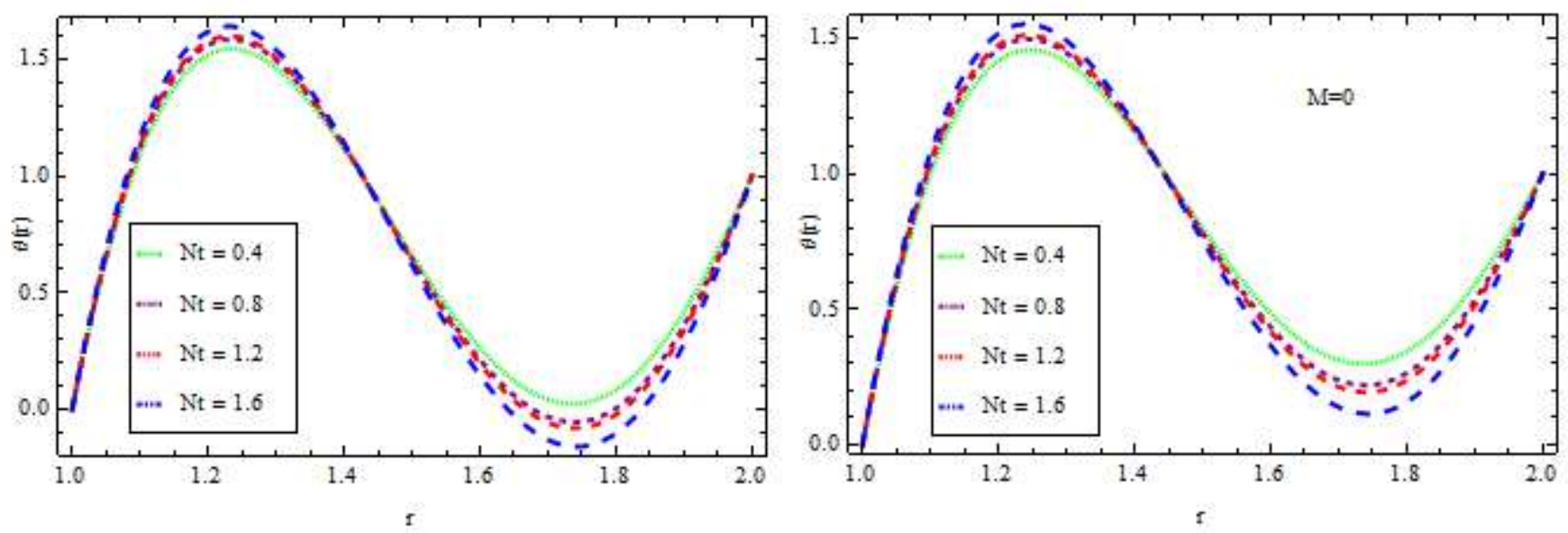

Figure 14. Impcat of Nt on $\theta(r)$ in VM case.
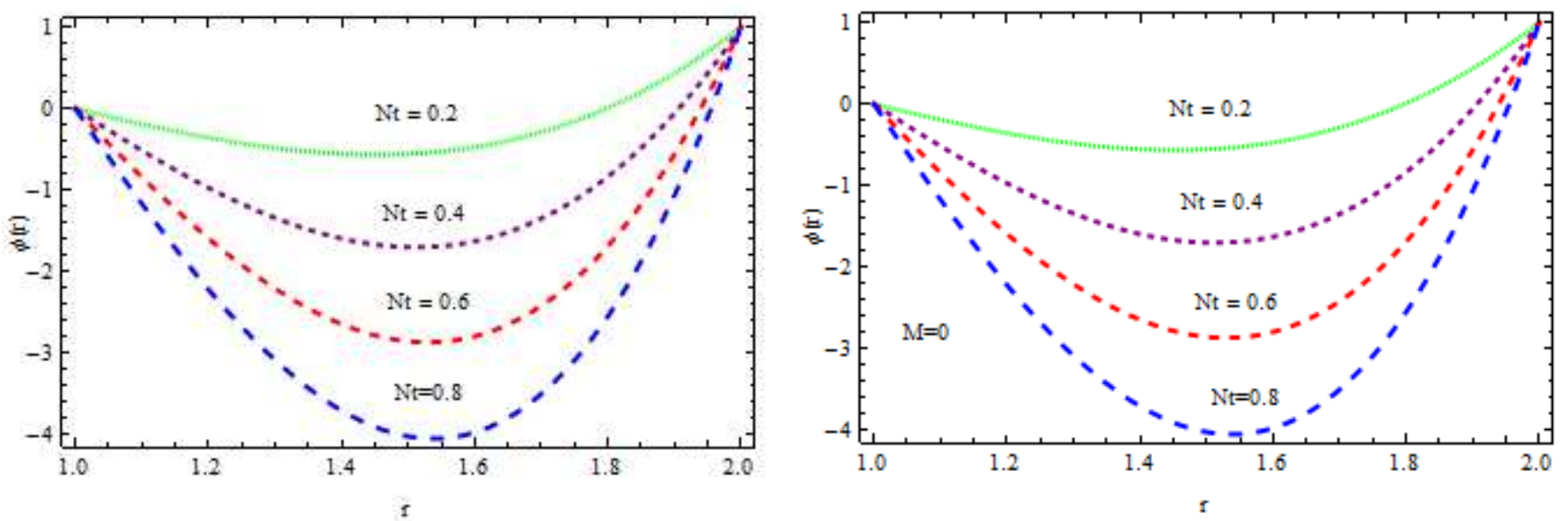

Figure 15. Impcat of $\mathrm{Nt}$ on $\phi(r)$ in RM case. 

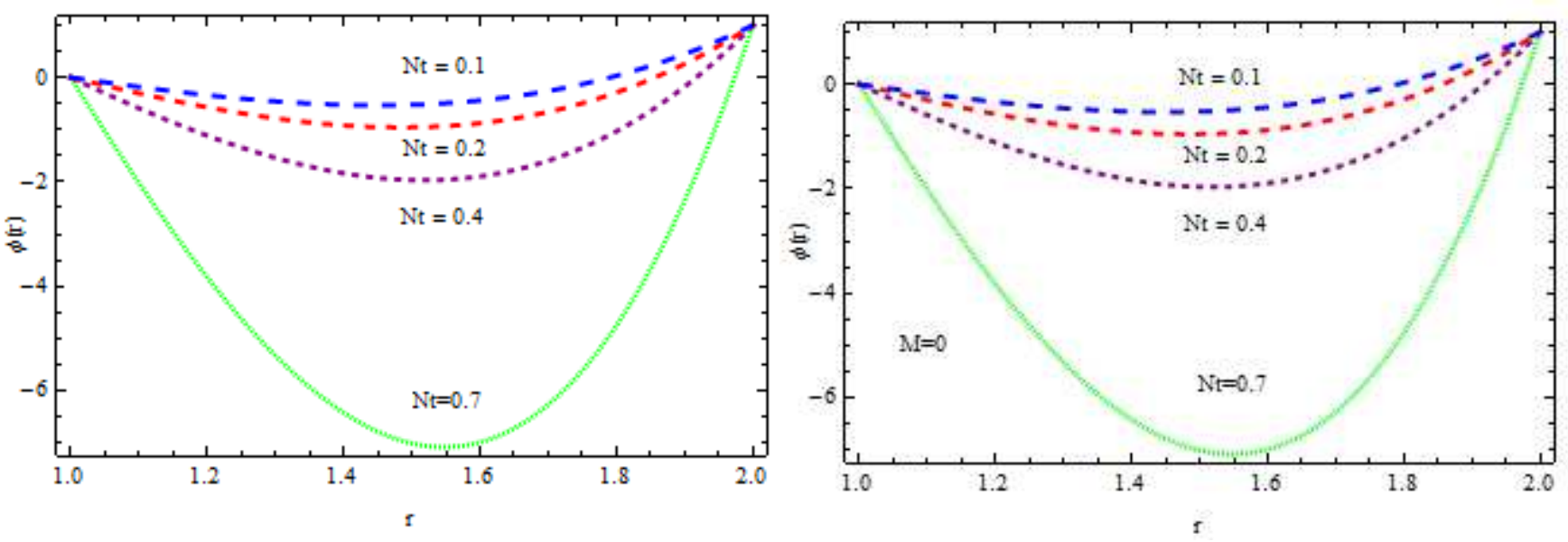

Figure 16. Impcat of $\mathrm{Nt}$ on $\phi(\mathrm{r})$ in $\mathrm{VM}$ case.
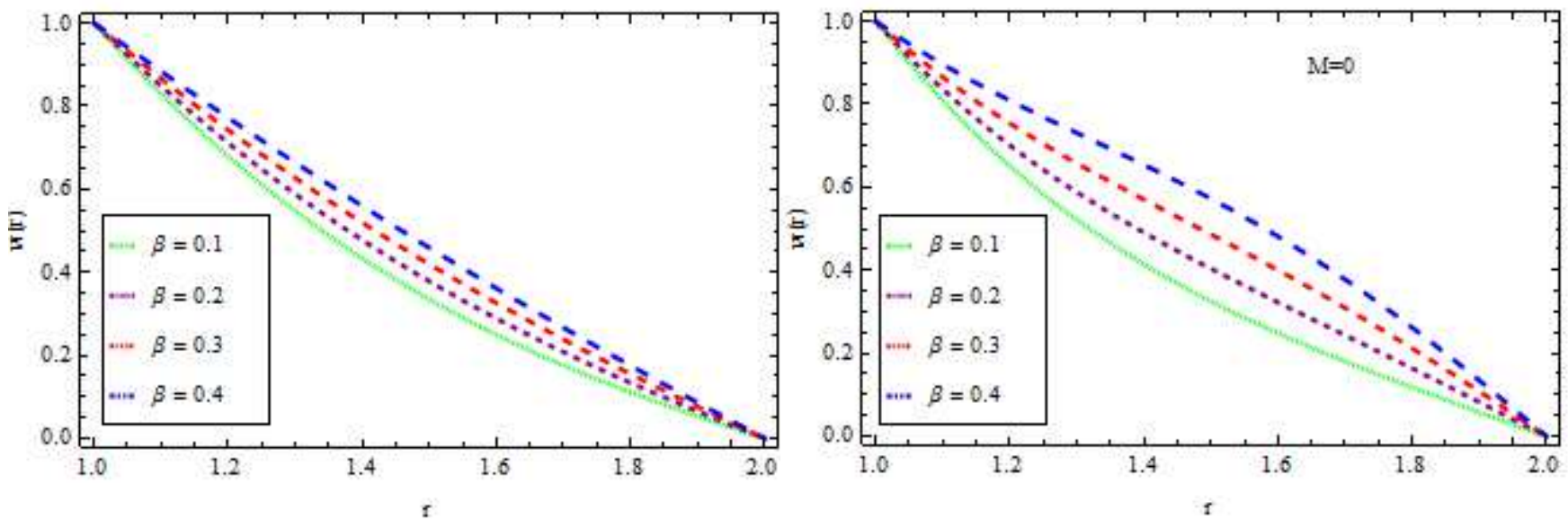

Figure 17. Impcat of Nt on w(r) in RM case. 

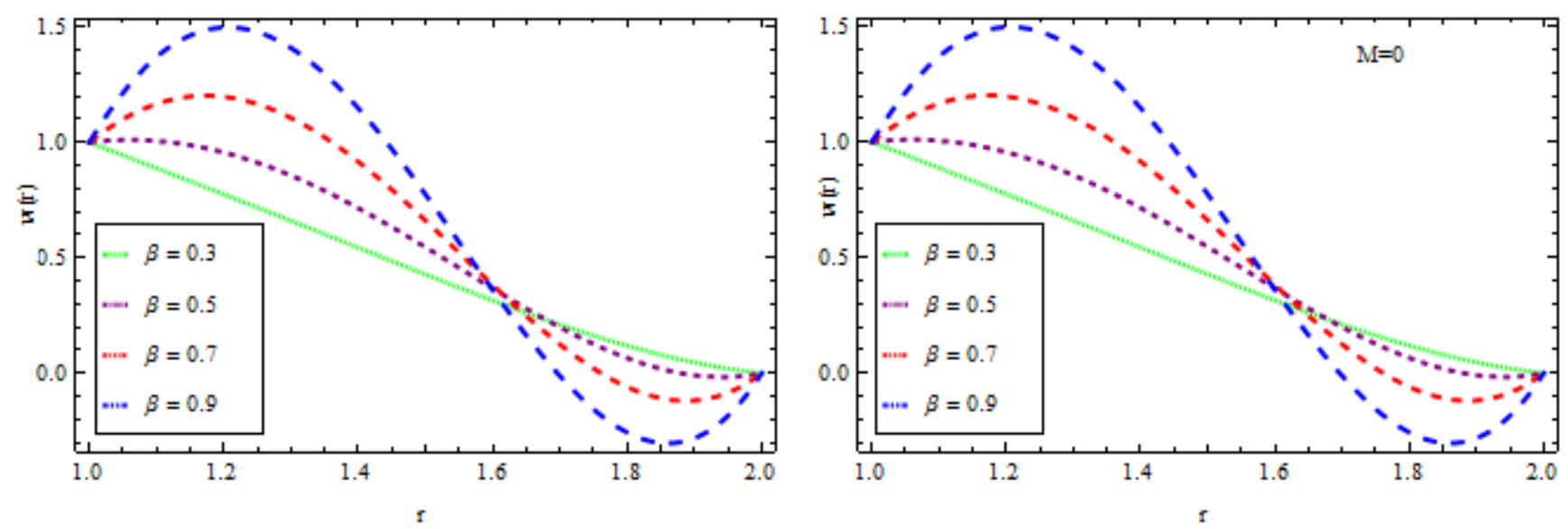

Figure 18. Impcat of $\beta$ on $w(r)$ in VM case.
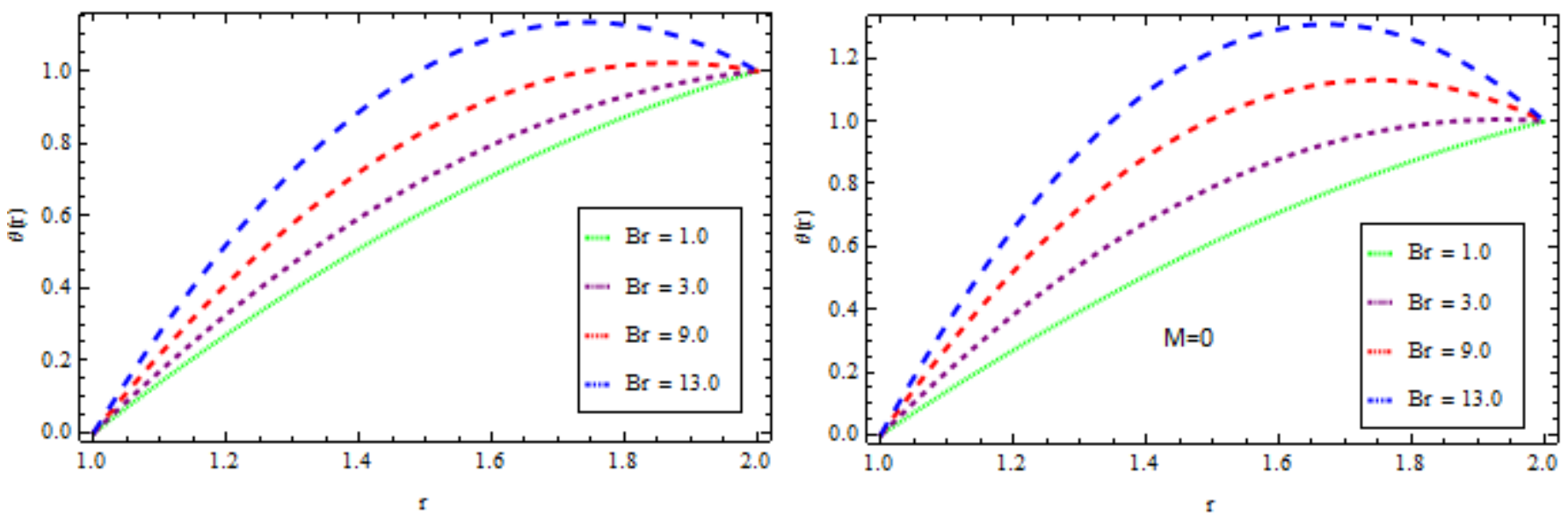

Figure 19. Impcat of $\mathrm{Br}$ on $\theta(\mathrm{r})$ in $\mathrm{RM}$ case. 

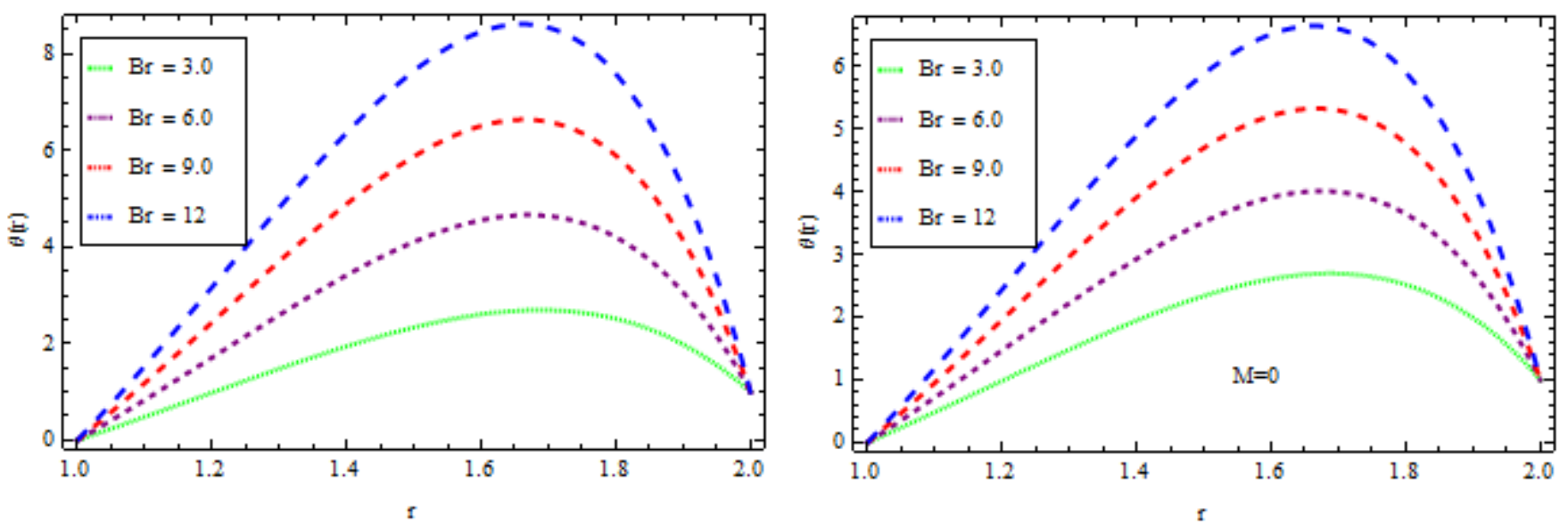

Figure 20. Impcat of $\mathrm{Br}$ on $\theta(\mathrm{r})$ in $\mathrm{VM}$ case.
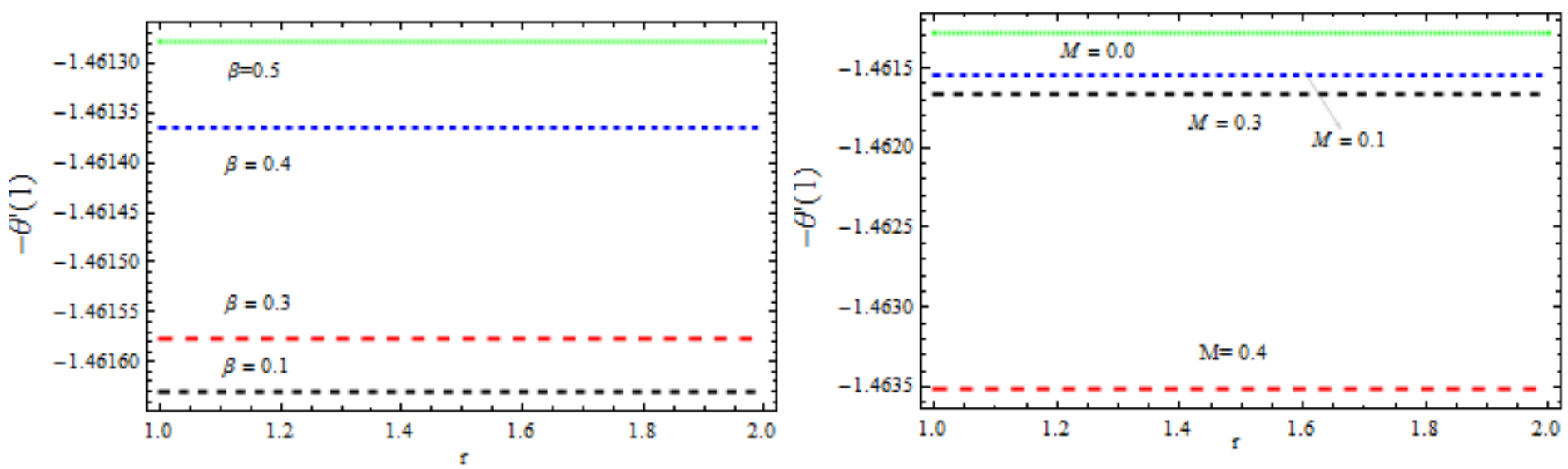

Figure 21,22 . Impcat of $\beta$ and $M$ on $-\theta^{\prime}$ (1) in VM case respectively. 

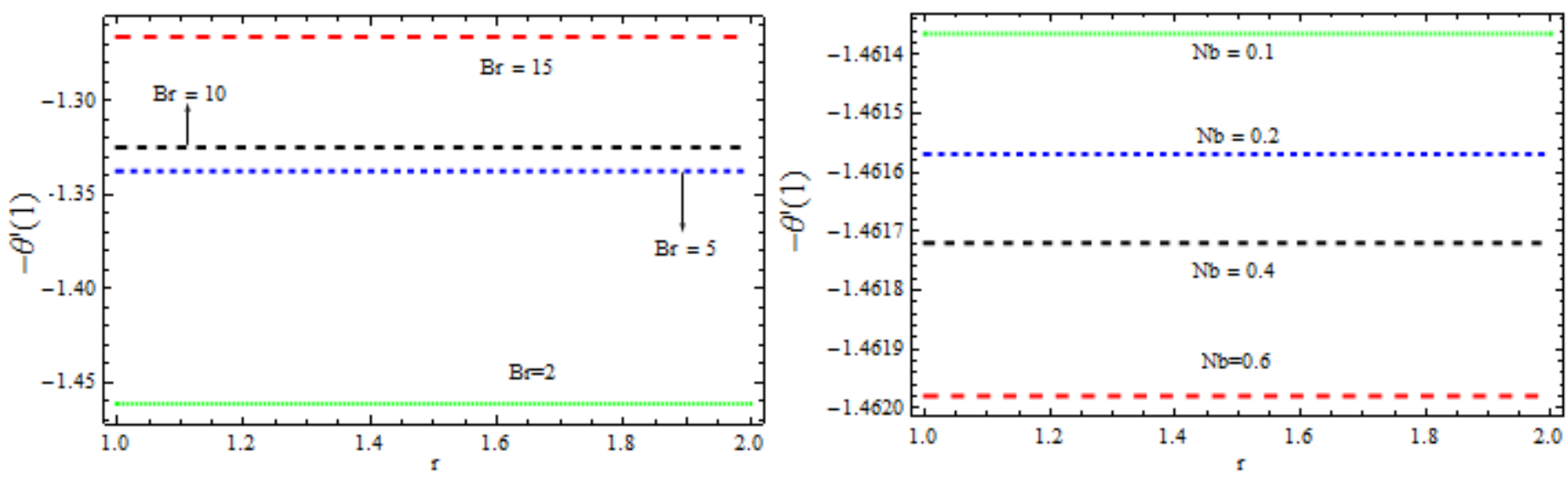

Figure 23, 24. Impcat of $\mathrm{Br}$ and $\mathrm{Nb}$ on $-\theta^{\prime}(1)$ in $\mathrm{RM}$ case.

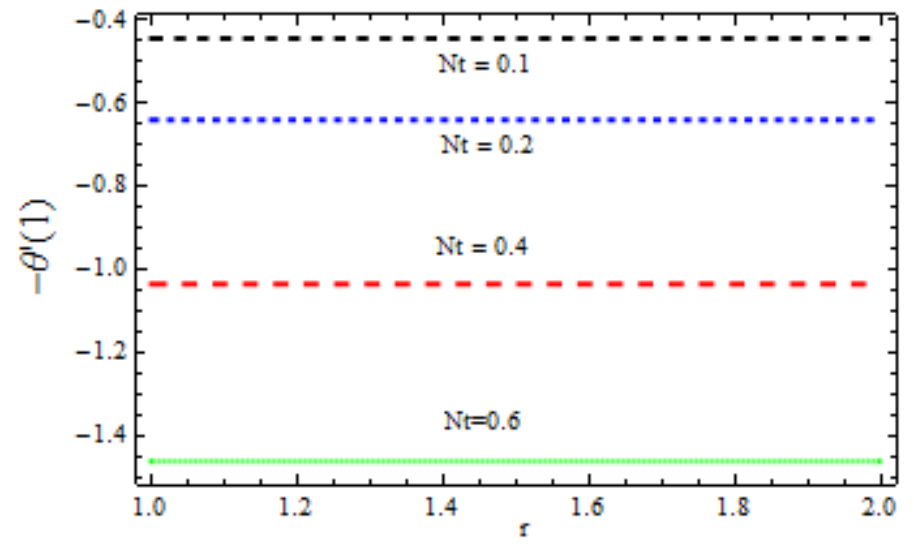

Figure 25. Impcat of $\mathrm{Nt}$ on $\theta^{\prime}(1)$ in RM case.

\section{Concluded remarks}

Regarding Reynolds and Vogel's situations, the significance of temperature-dependent viscosity in hydromagnetic heat and mass molecular diffusion of Third-grade fluid with particle concentration is investigated. Variable viscosity has a significant impact on all fluid flows. Viscosity factors can efficiently control the heat transport of resin in a die. For larger values of random motion and thermal 
radiation, the temperature gradient is enhanced in the first quarter of the section, but detrimental behavior occurs in the second half. Furthermore, the Brownian motion factor increases the concentration profile, but the thermophoresis factor shows a decrease. In Vogel's model, the thermoelectric field varies more strongly than in the Reynolds model case. In the RM case, the force on the whole surface of the wire and shear forces at the surface are greater than those in the VM case. When RM prevails over VM, the influence of nanomaterials is positive for force on the whole wires and shear forces at the surface.

Conflict of interest:The author(s) declare(s) that there are no conflicts of interest regarding the publication of this paper.

Data Availibility Statement: All relevant data are included in the manuscript. There is no data to support the present work.

Funding Statement: No funding was received about this manuscript. I will pay all publication fee after acceptance.

\section{References}

[1]. Middleman, S. (1977), Fundamentals of Polymer Processing, McGraw-Hill, NewYork, NY.28,10

[2]. Denn, M.M. (1980), Process Fluid Mechanics, Prentice-Hall, England Cliffs, NJ.

[3]. Akter, S. and Hashmi, M.S.J. (1999), "Analysis of polymer flow in a conical coating unit: a power law viscosity approach", Progress in Organic Coatings, Vol. 37 Nos1/2, pp. 15-22.

[4]. Siddiqui, A.M., Haroon, T. and Khan, H. (2009), "Wire coating extrusion in a pressure-type die in flow of a third grade fluid via homotopy perturbation method", Int. J. Nonlinear Sc. and Num. Simul, Vol. 10, pp. 99-112.

[5]. Sajid, M., Siddiqui, A.M. and Hayat, T. (2007), "Wire coating analysis using MHD Oldroyd 8constant fluid", International Journal of Engineering Science, Vol. 45Nos2-8, pp. 381-392.

[6]. Ayaz, M., Gul, T., Islam, S. and Altaf, M. (2015), "Analysis of ellis fluid in wire coating", VFAST Transactions on Mathematics, Vol. 7 No. 1, pp. 1-13.

[7]. Sajid, M. and Hayat, T. (2008), "Wire coating analysis by withdrawal from a bath of Sisko fluid", Applied Mathematics and Computation, Vol. 199 No. 1, pp. 13-22. 
[8]. Shah, R.A., Islam, S., Siddiqui, A.M. and Haroon, T. (2012a), "Heat transfer by laminar flow of an 8 elastico-viscous fluid in posttreatment analysis of wire coating with linearly varying temperature along the coated wire", Heat and Mass Transfer, Vol. 48 No. 6, pp. 903-914.

[9]. Shah, R.A., Islam, S., Siddiqui, A.M. and Haroon, T. (2012b), "Wire coating analysis with oldroyd 8 constant fluid by optimal homotopy asymptotic method", Computers and Mathematics with Applications. Vol. 63 No. 3, pp. 695-707.

[10]. Shafieenejad, I., Moallemi, N., Moallemi, N. and Novinzadeh, A.B. (2009), "An analytic approximation of wire coating analysis for third-grade magneto-hydrodynamic flow", Proceedings of the Institution of Mechanical Engineers, Part C: Journal of Mechanical Engineering Science, Vol. 223 No. 10, pp. 2273-2280.

[11]. Shah, R.A., Islam, S., Ellahi, M., Haroon, T. and Siddiqui, A.M. (2011), "Analytical solutions for heat transfer flows of a third grade fluid in case of posttreatment of wire coating", International Journal of Physical Sciences, Vol. 6 No. 17, pp. 4213-4223.

[12]. Nayak, M.K. (2016), "Wire coating analysis in MHD flow and heat transfer of a radiative third grade fluid with variable viscosity in a porous medium", American Journal of Heat and Mass Transfer, Vol. 3 No. 1, pp. 52-72.

[13]. Nayak, M.K., Dash, G.C. and Singh, L.P. (2014), "Steady MHD flow and heat transfer of a third grade fluid in wire coating analysis with temperature dependent viscosity"," International Journal of Heat and Mass Transfer, Vol. 79, pp. 1087-1095.

[14]. Choi, S.U.S. (1995), "Enhancing thermal conductivity of fluids with nanoparticles", ASMEPublicationsFed, Vol. 231, pp. 99-106.

[15]. Buongiorno, J. (2006), "Convective transport in nanofluids", Journal of Heat Transfer, Vol. 128 No. 3, pp. 240-250.

[16]. Kuznetsov, A.V. and Nield, D.A. (2010), "Natural convective boundary-layer flow of a nanofluid past a vertical plate", International Journal of Thermal Sciences, Vol. 49 No. 2, pp. 243-247.

[17]. Sheikholeslami, M. and Ganji, D.D. (2014), "Three dimensional heat and mass transfer in a rotating system using nanofluid", Powder Technology, Vol. 253, pp. 789-796.

[18]. Ellahi, R., Hassan, M. and Zeeshan, A. (2015), "Aggregation effects on water base Al2O3nanofluid over permeable wedge in mixed convection", Asia-Pacific Journal of Chemical Engineering. 
[19]. Shehzad, S.A., Abbasi, F.M., Hayat, T. and Alsaadi, F. (2014), "MHD mixed convective peristaltic motion of nanofluid with joule heating and thermophoresis effects", PLoS One, Vol. 9 No. 11, p. el11417.

[20]. Zeeshan Khan, Haroon Ur Rasheed et al. (2018C). Runge-Kutta 4th-order method analysis for viscoelastic Oldroyd 8-constant fluid used as coating material for wire with temperature dependent viscosity. Scientific Reports: https://doi.org/10.1038/s41598-018-32068-z

[21]. Zeeshan Khan, Rehan Ali Shah et al. (2018A). Effect of thermal radiation and MHD on nonNewtonian third grade fluid in wire coating analysis with temperature dependent viscosity. Alexandria Engineering Journal: 57, 2101-2112.

[22]. Zeeshan Khan, Rehan Ali Shah, et al.(2018B) Solution of Magnetohydrodynamic flow and Heat Transfer of Radiative Viscoelastic fluid with Temperature Dependent Viscosity in Wire Coating Analysis. Plos One: DOI: org./10.1371/journal.pone.0194196 (2018)

[23]. Sheikholeslami, M. and Ellahi, R. (2015), "Three dimensional macroscopic simulation of magnetic field effect on natural convection of nanofluid", International Journal of Heat and Mass Transfer. Vol. 89 , pp. 799-808.

[24]. Hussain, T., Hayat, T., Shehzad, S.A., Alsaedi, A. and Chen, B. (2015), "A model of solar radiation and joule heating in flow of third grade nanofluid", ZeitschriftFür Natur forschung A, Vol. 70 No. 3 , pp. 177-184.

[25]. Gireesha, B.J., Gorla, R.S.R. and Mahanthesh, B. (2015), "Effect of suspended nanoparticle on three-dimensional MHD flow, heat and mass transfer of radiating Eyring-Powell fluid over a stretching sheet", .

[26]. Ellahi, R., Raza, M. and Vafai, K. (2012), "Series solutions of non-newtoniannanofluids with Reynolds' model and Vogel's model by means of the homotopy analysis method", Mathematical and Computer Modeling, Vol. 55 Nos7/8, pp. 1876-1891.

[27]. Hayat, T., Khan, M.I., Waqas, M., Alsaedi, A. and Farooq, M. (2017), "Numerical simulation for melting heat transfer and radiation effects in stagnation point flow of carbon-water nanofluid", Combuter Methods in Applied Mechanics and Engineering, Vol. 315, pp. 1011-1024.

[28]. Ellahi, R., Zeeshan, A. and Hassan, M. (2016), "Particle shape effects on marangoni convection boundary layer flow of a nanofluid", International Journal of Numerical Methods for Heat and Fluid 
Flow, Vol. 26 No. 7, pp. 2160-2174.

[29]. Zeeshan Khan, Haroon Ur Rasheed et al. (2020A) Analysis of Erying-Powell Fluid Flow Used as a Coating Material for Wire with Variable Viscosity Effect Along with Thermal Radiation and Joule Heating. Crystal. doi.org/10.3390/cryst10030168

[30]. Zeeshan Khan,Haroon Ur Rasheed et al. (2020B) Investigation of Wire Coating Using Hydromagnetic Third-Grade Liquid for Coating along with Hall Current and Porous Medium. Mathematical Problem in Engineering, Volume 2020 |Article ID 4218717.

[31]. Mahanthesh, B., Gireesha, B.J., Gorla, R.R., Abbasi, F.M. and Shehzad, S.A. 2016), "Numerical solutions for magnetohydrodynamic flow of nanofluid over a bidirectional non-linear stretching surface with prescribed surface heat flux boundary", Journal of Magnetism and Magnetic Materials, Vol. 417, pp. 189-196. HFF

[32]. Turkyilmazoglu, M. (2016), "Flow of nanofluid plane wall jet and heat transfer", European Joumal of Mechanics - B/Fluids, Vol. 59, pp. 18-24.

[33]. Mahanthesh, B., Mabood, F., Gireesha, B.J. and Gorla, R.S.R. (2017b), "Effects of chemical reaction and partial slip on the three-dimensional flow of a nanofluid impinging on an exponentially stretching surface", The European Physical Journal Plus, Vol. 132 No. 3, p. 113.

[34]. Shirvan, K.M., Mamourian, M., Mirzakhanlari, S., Rashimi, A.B. and Ellahi, R. (2017), "Numerical Variable investigation of heat exchanger effectiveness in a double pipe heat exchanger filled with nanofluid: a sensitivity analysis by response surface methodology", Powder Technology, viscosity Vol. 313, pp. 99-111.

[35]. Mahanthesh, B., Gireesha, B.J., Shashikumar, N.S. and Shehzad, S.A. (2017a), "Marangoni convective MHD flow of SWCNT and MWCNT nanoliquids due to a disk with solar radiation and irregular heat source", Phvsica E: Low-Dimensional Systems and Nanostructures, Vol. 94, pp. 25-30.

[36]. Shirvan, K.M., Mamourian, M. and Ellahi, R. (2017a), "Numerical investigation and optimization of mixed convection in ventilated square cavity filled with nanofluid of different inlet and outlet port", International Journal of Numerical Methods for Heat and Fluid Flow, Vol. 27 No. 9 , pp. 2053-2069. [37]. Turkyilmazoglu, M. (2017), "Condensation of laminar film over curved vertical walls using single and two-phase nanofluid models", European Journal of Mechanics - B/Fluids, Vol. 65, pp. 184-191. [38]. Mitsoulis, E. (1986), "Fluid flow and heat transfer in wire coating: a review", Advances in 
Polymer Technology, Vol. 6 No. 4, pp. 467-487.

[39]. Shirvan, K.M., Ellahi, R., Mamourian, M. and Moghiman, M. (2017b), "Effects of wavy surface characteristics on natural convection heat transfer in a cosine corrugated square cavity filled with nanofluid", International Journal of Heat and Mass Transfer, Vol. 107, pp. 1110-1118.

[40]. Shirvan, K.M., Mamourian, M., Mirzakhanlari, S., Rahimi, A.B. and Ellahi, R. (2017), "Numerical study of surface radiation and combined natural convection heat transfer in a solar cavity receiver", Intemational Journal of Numerical Methods for Heat and Fluid Flow, Vol. 27 No. 10, pp. 2385-2399.

[41]. Mahanthesh, B., Gireesha, B.J. and Gorla, R.S. (2016a), "Mixed convection squeezing threedimensional flow in a rotating channel filled with nanofluid", International Journal of Numerical Methods for Heat and Fluid Flow, Vol. 26 No. 5, pp. 1460-1485.

[42]. Khan, J.A., Mustafa, M., Hayat, T., Turkyilmazoglu, M. and Alsaedi, A. (2017), "Numerical study of nanofluid flow and heat transfer over a rotating disk using Buongiorno's model", International Journal of Numerical Methods for Heat and Fluid Flow, Vol. 27 No.1, pp. 221-234.

[43]. Hayat, T., Khan, M.I., Waqas, M., Yasmeen, T. and Alsaedi, A. (2016), "Viscous dissipation effect in flow of magneto nanofluid with variable properties", Journal of Molecular Liquids, Vol. 222 , pp. 47-54.

[44]. Muhammad, T., Alsaedi, A., Hayat, T. and Shehzad, S.A. (2017), "A revised model for Darcy Forchheimer three-dimensional flow of nanofluid subject to convective boundary condition", 0 Results in Phvsics, Vol. 7, pp. 2791-2797. 